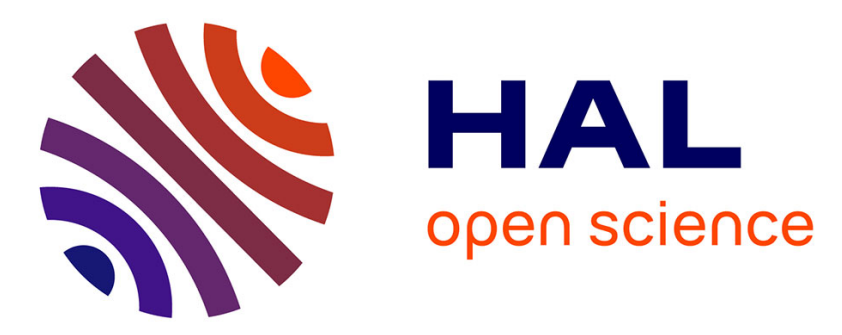

\title{
Multi-Agent Simulations to Explore Rules for Rural Credit in a Highland Farming Community of Northern Thailand
}

Cécile Barnaud, Francois Bousquet, Guy Trebuil

\section{- To cite this version:}

Cécile Barnaud, Francois Bousquet, Guy Trebuil. Multi-Agent Simulations to Explore Rules for Rural Credit in a Highland Farming Community of Northern Thailand. Ecological Economics, 2008, 66, pp.615-627. hal-00609663

\section{HAL Id: hal-00609663 https://hal.science/hal-00609663}

Submitted on 19 Jul 2011

HAL is a multi-disciplinary open access archive for the deposit and dissemination of scientific research documents, whether they are published or not. The documents may come from teaching and research institutions in France or abroad, or from public or private research centers.
L'archive ouverte pluridisciplinaire HAL, est destinée au dépôt et à la diffusion de documents scientifiques de niveau recherche, publiés ou non, émanant des établissements d'enseignement et de recherche français ou étrangers, des laboratoires publics ou privés. 


\title{
Multi-Agent Simulations to Explore Rules for Rural Credit in a Highland Farming Community of Northern Thailand
}

\author{
Cécile BARNAUD*¹, ${ }^{1,}$ François BOUSQUET ${ }^{2}$, Guy TREBUIL ${ }^{2}$
}

The final version of this paper has been published in Ecological Economics :

Barnaud C., Bousquet F., Trébuil G. (2008) Multi-Agent Simulations to Explore Rules for Rural Credit in a Highland Farming Community of Northern Thailand. Ecological Economics, 66 (4): 615627.

\begin{abstract}
Multi-agent systems (MAS) open new modelling and analysis perspectives in ecological and social sciences. An original characteristic of the Companion Modelling (ComMod) approach adopted in this case study is the co-construction and use of a MAS model with and for local stakeholders such as farmers and local administrators. Alternating iteratively field and modelling activities, this approach facilitates collective learning among local stakeholders and between them and the researchers. Combining the use of MAS models with Role-Playing Games (RPG), the described experiment aimed to facilitate collective decision-making in a socially heterogeneous community of small farmers in mountainous northern Thailand about the local rules for the allocation of rural credit to allow a more equitable and extensive process of expansion of non-erosive perennial crops in a watershed prone to erosion. This paper presents the MAS model and the results of a series of simulations exploring the ecological, social and economic effects of various rules for formal and informal credit suggested by the villagers-participants. Six scenarios considered as pertinent to further explore the participants' suggestions were defined based on different combinations among the following three variables: (i) Duration for the reimbursement of loans, (ii) Mode of allocation of formal credit among three different types of farms, (iii) Configuration of networks of acquaintances for access to informal credit.

Drawing on this case study, we first elaborate on the potential of bottom-up models such as MAS to analyze the functioning of agricultural systems, in particular farm differentiation and rural credit dynamics. We highlight the ability of MAS to deal with interactions between social and ecological dynamics and to take into account social interactions, in particular the concept of social capital which is a determining factor when dealing with sustainability issues. The second question addressed in this paper deals with the potential and limits of MAS models to support a bottom-up (or participatory) modelling approach. This experiment suggests that the usefulness of models relies much more on the modelling process than on the model itself, because a model is usually useless if it is misunderstood by its potential users, or if it does not respond to their current preoccupations. The intuitive representation of real systems provided by MAS and their high flexibility are the two underlined characteristics favouring their appropriation by local stakeholders.
\end{abstract}

Key words: Multi-agent systems; companion modelling; participatory modelling; rural credit; farm differentiation

\footnotetext{
${ }^{1}$ Department of Geography, Paris X University, France.

* Corresponding author: Tel.: +66 (0) 867759758; fax: ++ 66 (0) 22192057. E-mail: cecile.barnaud@cirad.fr

${ }^{2}$ GREEN (Management of renewable resources and the environment) Research Unit, CIRAD, France \&

Companion Modelling Project, Faculty of Science, Chulalongkorn University, Bangkok, Thailand.
} 


\section{Introduction}

Thanks to advances in the field of distributed artificial intelligence, multi-agents systems (MAS) can now be used to run simulations of social phenomena based on their computerized representations, and to apply new types of experimental methods in social sciences (Axelrod 1997, Gilbert and Troitzsch 1999, Janssen and De Vries 1998, Moss and Edmunds 2005). A MAS can be defined as a collection of autonomous entities interacting with each other and with their environment (Ferber 1999). Contrary to traditional modelling techniques, MAS are not expressed in terms of variables, functions and equations, but in terms of agents, objects and environment. In addition to providing a natural and intuitive description of a system, they can capture emergent phenomena resulting from the interactions of individual entities. This is why they are sometimes called "bottom-up" models (Boulanger and Bréchet, 2005, p 344) and are closely linked to the concept of complex systems.

In the field of economy, MAS provide an alternative to classical economic thinking (Arthur 1991, Arthur et al. 1997, Jager et al. 2000, Kirman 1999, Rouchier and Bousquet 1998, Tesfatsion and Judd, 2006). In conventional economic theories, the behaviour of a group of individuals is represented by a single average meta-actor. General interest is seen as the sum of individual interests. Moreover, individuals' behaviours are formalised following a rational-actor approach, i.e. as Homo economicus which are self-regarding individuals maximising their own well-being with unlimited cognitive resources. While these traditional economic models have proven their usefulness in many situations, the above-cited authors argue that these models fail to capture some important nuances of reality. Instead, the behaviour of a group of individuals can be seen as a set of interactions among heterogeneous individuals, generating aggregate phenomena that are different from the behaviour of an average meta-actor (Kirman 1999). Alternative models of human actors' behaviours also emphasize that actors take decisions with limited cognitive resources, as their perception of reality is biased and incomplete, and they are limited in their capacity to predict the future. Moreover, human actors are not necessarily self-regarding and isolated (Jager et al, 2000). Social dimensions and interactions such as imitation, exchanges of information, mutual aid and cooperation can be key factors affecting both micro-level processes and macro-level outcomes. MAS are seen as a promising tool to study such alternative economic theories.

MAS are of particular interests to researchers in the field of renewable resource management (Bousquet and Le Page 2004, Lansing and Kremer 1993). Several adapted MAS simulation platforms were developed such as Cormas (Bousquet et al. 1998), Netlogo (Wilensky 1999), Repast (North et al. 2006) or Swarm (Minar et al. 1996). After comparing the strengths and weaknesses of six main families of modelling techniques (such as macroeconometric models, system dynamics models, Bayesian networks, etc.) to assess environmental, economic and social impacts of development policies, Boulanger and Bréchet (2005) concluded that MAS was the most promising one to deal with sustainable development issues.

An original characteristic of the Companion Modelling (ComMod) approach adopted in this case study is the co-construction of the MAS model with local stakeholders (such as farmers and local administrators) and the use of MAS simulations with them to facilitate collective learning among them and between them and the researchers (Barreteau et al. 2003, Bousquet et al. 1999). Compared to classical modelling processes in which researchers build models on their own before presenting them to policy-makers, such an approach is based on the assumption that an increased participation of local stakeholders in the construction of model dealing with issues affecting them would benefit not only the local stakeholders, but also the researchers and the policy-makers. ComMod triggers stakeholder participation by adopting an iterative approach alternating field and modelling activities in a cyclical way to ensure that the researchers' assumptions are continuously confronted to the field situation and 
the feedbacks from the local stakeholders integrated in the model. This approach is used with two possible aims: learn on systems or support collective decision processes in these systems. In both cases, researchers and local stakeholders iteratively learn from each other through interactions mediated by an evolutionary model (Barreteau et al, 2003). ComMod has been recently applied in many places in the world (D'Aquino et al. 2003, Etienne 2003) and at a dozen sites in Southeast Asia (Bousquet et al. 2005). It often (but not necessarily) combines the use of MAS models with Role-Playing Games (RPG) to facilitate local stakeholders' participation and discussions among them, like in this experiment.

The MAS model presented in this paper was built to facilitate collective decisionmaking in a socially heterogeneous community of small farmers in mountainous northern Thailand about the local rules for the allocation of rural credit to allow a more equitable and extensive process of expansion of non-erosive perennial crops in a watershed prone to erosion (Barnaud et al. 2006). This model explores the interrelated roles of formal and informal credit and the ecological and socio-economic impacts of various credit rules. Formal credit corresponds to institutionalized credit funds whereas informal credit is seen as loans settled among villagers, either without interests within networks of acquaintances, or with high interest rates when usurers are involved. This case study addresses three of the main methodological challenges for models dealing with sustainability issues identified by Boulanger and Bréchet ${ }^{3}$ (2005). First, it requires an interdisciplinary approach to trigger the interactions between the ecological dynamics of soil erosion and the socio-economic dynamics related to rural credit and farm differentiation. Second, the model adopts a localglobal (or bottom-up) perspective to analyze the effects at the watershed and community levels of the farmers' individual behaviours and of the interactions among them. Third, Boulanger and Bréchet (2005) also mention stakeholder participation as a main challenge for modelling processes dealing with sustainable development.

This article is aimed at answering two questions. First, what are the potential and limits of bottom-up models such as MAS to explore the functioning of agricultural systems, in particular farm differentiation and rural credit dynamics? Second, what are the potential and limits of MAS models to support a bottom-up modelling approach, i.e. a participatory modelling process in which models are conceived and used with and for local stakeholders? Following a description of the study site, the conducted ComMod process and the MAS model, we analyze the results of a series of simulations exploring the ecological, social and economic effects of various rules for formal and informal credit. The two above mentioned questions are then discussed in light of these results. We come back in conclusion to the theoretical discussions in the field of economy to highlight which economic theories our findings support.

\section{Materials \& methods}

\section{A cyclical process combining Multi-Agent Systems with Role Playing Games}

The main successive phases of a ComMod cycle are generally as follows: (i) Characterization of the problem, (ii) Modelling, i.e converting existing knowledge into one or several formal tools to be used as simulators; and (iii) Simulations to explore various scenarios of solutions. In this case study, the ComMod process combined the use of field surveys, individual interviews, focused group debates and two types of simulations tools: Role-Playing Games (RPG) and Multi-Agent Systems (MAS). In each cycle, the RPG used with the stakeholders is a simplified version of the MAS: the agents in the model correspond to the roles in the game,

\footnotetext{
${ }^{3}$ Boulanger and Bréchet (2005) identified five main methodological challenges for models dealing with sustainability issues: (i) interdisplinary approach to trigger human-nature interactions, (ii) uncertainty management, (iii) long-range view to deal with temporal externalities, (iv) local-global perspective for spatial externalities, and (v) stakeholder participation for social externalities.
} 
the spatial interface of the model corresponds to the gaming board, the time step of the model corresponds to the gaming round, etc. The main difference is that while in the RPG decisions are taken by real players, in the MAS the corresponding decision making processes are modelled. The game is a way to "open the black box of the model": it allows the players to understand, and therefore criticize and validate the model suggested by the research team (Barreteau et al. 2001). The learning process focusing on a problem in a ComMod cycle might raise new problems and questions that can be examined in a following cycle with new adapted RPG and MAS model. This is what happened in this experiment (figure 1).

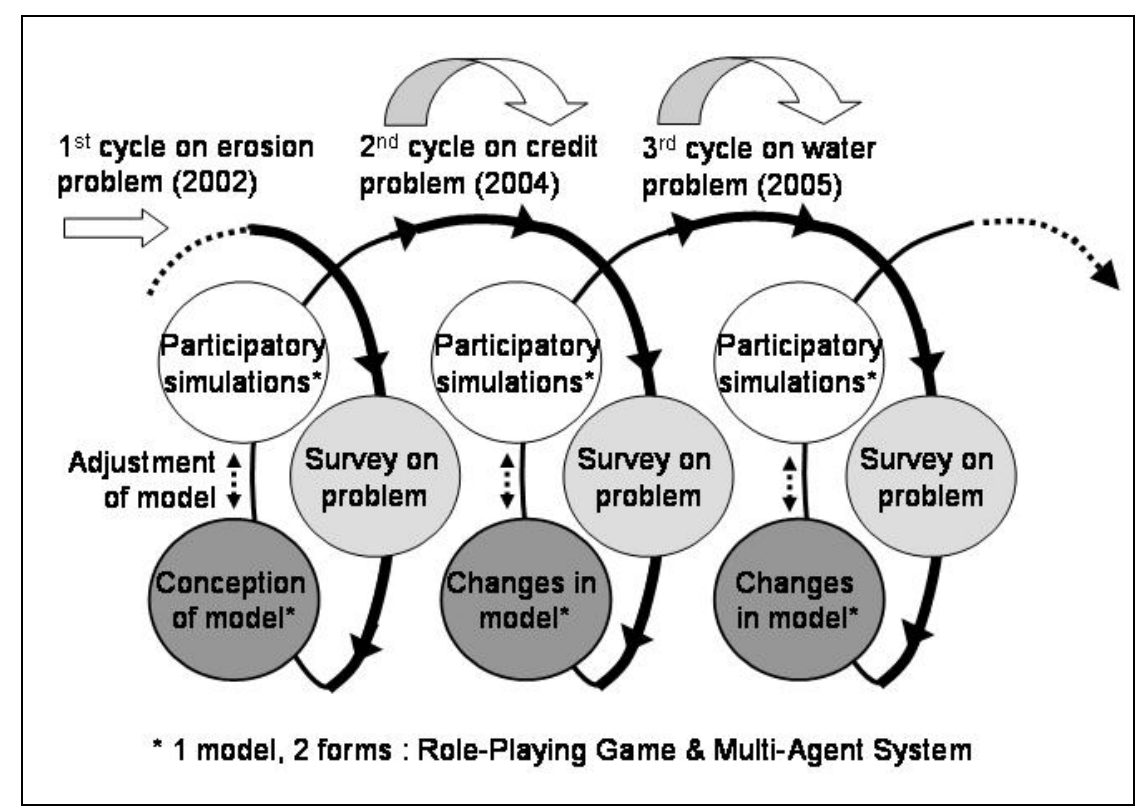

Figure 1. The iterative companion modelling process alternating field and laboratory activities implemented in Mae Salaep village, Chiang Rai Province, northern Thailand. Natural Resource Management issues addressed at Mae Salaep study site

In the Akha village of Mae Salaep located in Chiang Rai province, following more than two decades of integration in the market economy, the process of commercial diversification based on horticultural productions led to an extensive social differentiation among farming households with various economic interests and land-use strategies (Trébuil et al. 1997). As the traditional rotational system is replaced by a permanent cash cropping-based agriculture, the increased risk of soil erosion in the upper catchments perceived by lowlanders threatens ethnic minority highlanders with further restrictions regarding their access to farm land. In this context, the first implemented ComMod cycle focused on reaching a common understanding on the relationship between the risk of soil erosion and crop diversification (Trébuil et al. 2002). During this cycle, the villagers validated the agro-ecological aspects of the model suggested by the researchers. They discussed and agreed on the need to expand the coverage of non-erosive perennial cash crops in the catchment, seeing them as a promising solution limiting soil erosion while securing higher and more stable incomes. But the participants also pointed to the fact that only the relatively well-off households could currently invest in perennial crops. Therefore they requested to implement a second ComMod cycle focusing on the socioeconomic dynamics related to the adoption of perennial crops (figure 1). In particular, as the possibility to invest in perennial crops is highly dependent on access to credit because of the long delay between planting and the first harvests, new rules for the allocation of rural credit needed to be found to support the establishment of such plantations in resource-poor farmers' fields (Barnaud et al. 2006a). Later on, as these plantations were expanding and requested more and more irrigation water, social tension 
occurred among villagers because of a growing gap between water availability and needs, and the participants requested to examine this water problem in a third ComMod cycle (Barnaud et al. 2007b). In this article, we focus on the MAS modelling and simulating process conducted in the second cycle regarding credit.

\section{Description of the socio-ecological system and the situation regarding credit}

The three main types of farming households in this Akha village differ by their amounts of land resources and capital, and subsequent differentiated socio-economic strategies. Type A farming households have small market integrated farms, type B medium-sized and conservative farms, and type $\mathrm{C}$ large farms with diverse commercial productions.

Compare to annual cash crops such as maize or ginger, perennial crops can provide higher and more stable incomes. They also present the advantage of being less labour intensive and therefore leaving more time to family labours for off-farm employment, which is an important source of income in the area. Two perennial crops dominate in the catchment: lychee, a high input and high economic risk crop accessible to only well-off farmers, and the more recently introduced green Assam tea, named “the poor man's perennial crop”. With no external input required, a shorter duration from planting to first pickings, and more stable farm gate prices, Assam tea is accessible to a broader range of villagers, but not all of them yet because of a lack of access to appropriate credit.

The situation regarding credit can be summarized as follows. Formal and informal credit systems co-exist in the village. Concerning formal credit, besides a village fund providing small loans with average interest rates, a government fund providing larger sums, and without interests, was launched in 2002. But this profitable source of credit is currently only accessible to well-off households because they are the only ones who can reimburse the loan on time within a year. This unequal distribution of the government fund is partially compensated by its redistribution through informal loans within networks of acquaintances. However, as those networks are usually small and quite homogeneous, there still exists a number of smallholders, acquainted with households as poor as them, with no access to this source of credit.

\section{Methodology used in the second ComMod cycle focusing on credit}

According to the villagers' request to focus on socio-economic constraints to the adoption of perennial crops, a complementary farm survey was carried out to gather detailed information on these dynamics (credit, off-farm employment and price fluctuations). The RPG and MAS model used in the previous cycle were modified to conceive a new set of RPG and MAS model adjusted to the villagers' socio-economic preoccupations. A detailed description of the way the RPG and MAS models were adjusted is available in (Barnaud et al. 2007a). Both tools were used with villagers during a three day long participatory modelling and simulation workshop held in the village school. The objective of this workshop was to stimulate exchanges about the credit problem (i) between researchers and local stakeholders (did the representation of the situation suggested by the researchers correspond to the villagers' perceptions and preoccupations?), and (ii) among local stakeholders themselves, i.e. among the different categories of farming households (what possible collective solutions could be found to solve the problem of unequal access to perennial crops?). On the first day, gaming sessions with twelve players representing the different types of farming households were conducted to stimulate exchanges of perceptions on the problem and discussions about possible solutions (figure 2.a). On the second day, individual interviews were conducted to elucidate the players' behaviours during the game, and to assess the model of the game, i.e. to let the local stakeholders criticize or validate the researchers' assumptions on the credit situation. The research team had conceived before the workshop a conceptual model 
formalising their assumptions regarding the farmers' behaviours and the main interacting social and ecological dynamics. This conceptual model had been used to prepare the roleplaying game and to build a temporary version of the associated MAS model. After the first two days of the workshop, this temporary MAS model was quickly adapted to take into account the new knowledge acquired during the game and the critics of the game made by the participants. Then on the third day of the workshop, participatory sessions of simulations with this improved and validated MAS model were conducted to explore the scenarios suggested by the villagers during the first day discussions (figure 2.b). Later on, this MAS model was more thoroughly improved and further simulations were conducted in the lab to analyze thoroughly the functioning of the credit system in the model and the scenarios suggested by the villagers.

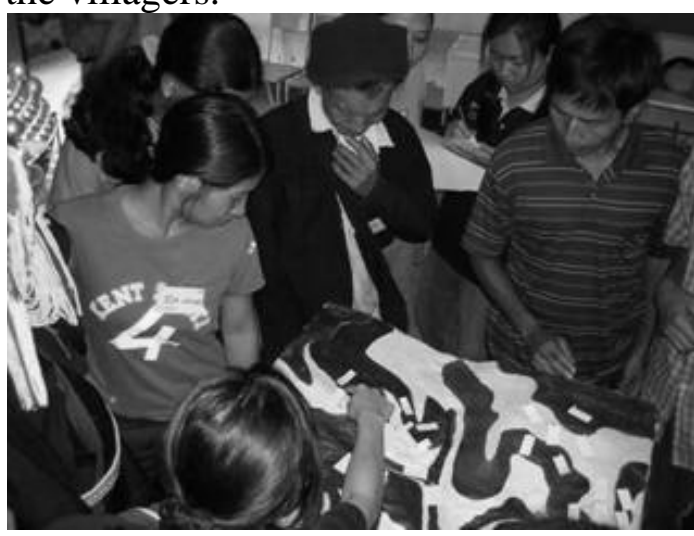

Figure 2a. Each participant plays the role of a farmer managing a set of fields located on a gaming board representing a catchment. The 12 players are given various initial amounts of land, labour and capital and can play the equivalent of 6 cropping years within a day. This stimulates discussions among them about their problems.

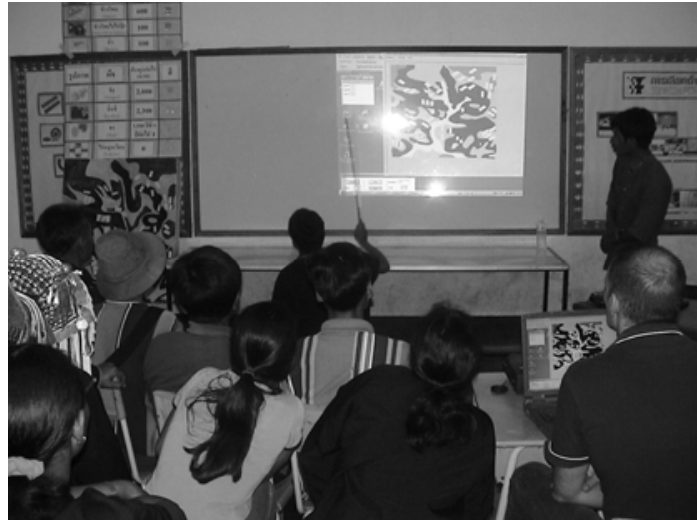

Figure 2b. An agent-based model, very similar the game, is used to explore collectively scenarios of solutions suggested by the participants. Compare to the game, the computer simulations allow to explore more various and longer-term scenarios (15 years) within a shorter time.

\section{Description of the MAS model}

The MAS model was implemented under the CORMAS (Common pool Resources and MultiAgent Systems, http://cormas.cirad.fr) simulation platform specifically designed to model interactions between ecological and social dynamics for renewable resource management (Bousquet et al. 1998).

\section{Modelling assumptions}

There is no process of inheritance because the duration of the simulation does not exceed 15 years, which was considered sufficient to analyse the dynamic of investment in perennial crops.

\section{Model entities and structure}

The model main social agents (farmer, usurer -or loan shark-, government and village funds), passive objects (market, weather), and spatial entities ("cell” as the elementary spatial unit on the grid, "fields" of various size depending on the farm type, and "farm" made of several fields) and their relationships are presented in Figure 3. In this UML class diagram, one can see the attributes (variable or permanent characteristics) and methods (possible actions during simulations) assigned to each model's entity. 


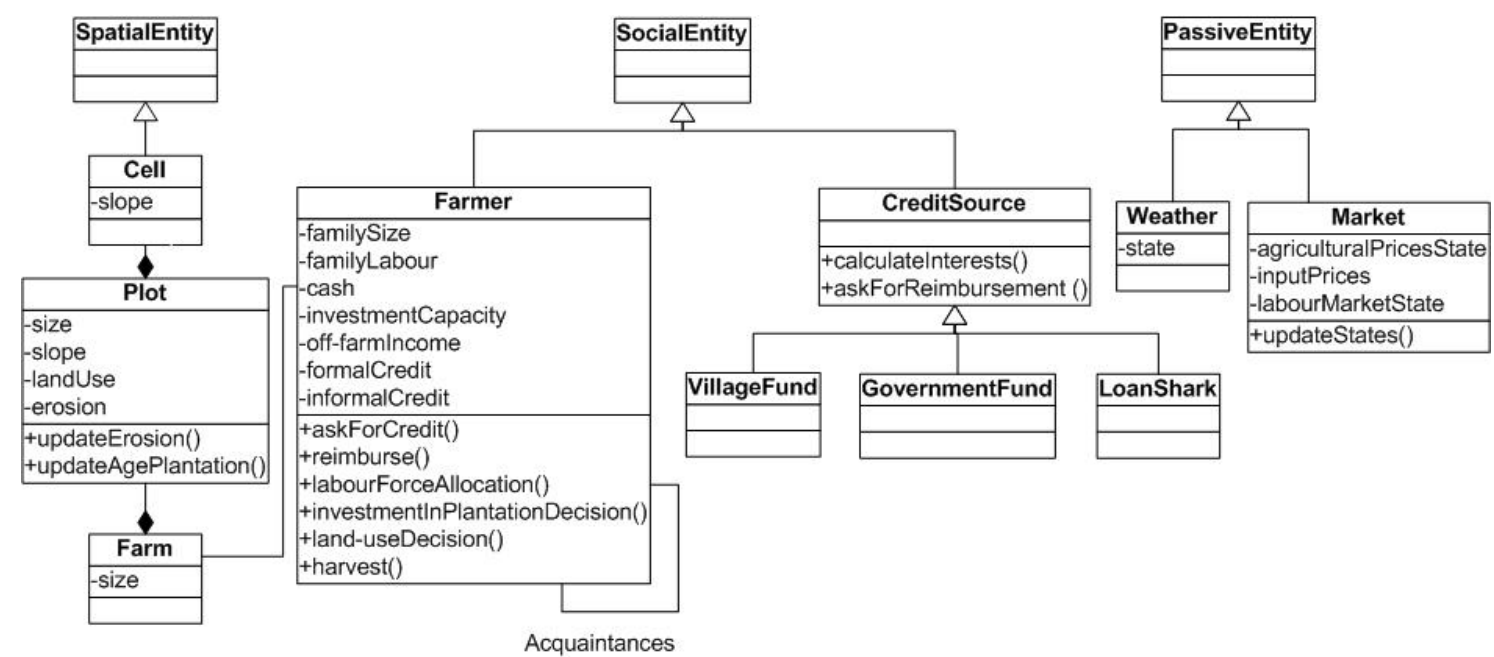

Figure 3. Class diagram of the model describing its entities and their relationships.

Twelve agent farmers (3, 6 and 3 for types A, B, and C respectively) are represented in the model, like in the associated RPG. This corresponds to the actual farm distribution in the village. In the model, the three types of farmers differ by their initial amounts of land per capita and capital resources, as well as the annual family consumption needs (well-off families have higher needs than poor ones).

Each farmer operates with 1, 2 or 3 family labourers which he will decide each year to assign either to off-farm or farming activities. This labour constraint was introduced in the model to take into account the fact that perennial crops are less labour-intensive than annual field crops and allow farmers to seize more off-farm employment opportunities.

To represent networks of informal credit, each farmer is assigned two acquaintances selected among the other agents.

Sequential flow of information during simulation and farmers decision making process

The time step is the crop year and each simulation is made of 15 time steps, i.e. 15 successive crop years. Each year, each agent "Farmer" starts to search credit if needed, i.e. if his available cash is not sufficient to pay for the annual agricultural inputs. Each farmer will successively try to secure the required loan from the government fund (with zero interest), his acquaintances, the village fund, and, as a very last resort, usurers. When a farmer receives a loan request from one of his acquaintances, he will accept on the condition that his cash available is above a certain threshold. After looking for credit, the farmer decides whether to seize off-farm employment opportunities or not. This determines the amount of family labour available on the farm. Then each farmer allocates a choice of crops to his fields. All farmers, whatever their socio-economic type, have the same decision-making process ${ }^{4}$. The decision making process regarding crop allocation is as follows. The farmer allocates a crop to a field, and the corresponding costs of external inputs are deducted from the available cash. Then he repeats the same process for all his fields. For the first field, all farmers will decide to grow rice for home consumption. This decision does not necessarily correspond to an economic optimum. It is rather related to a cultural preference. Then, for the other fields, the decision to grow the different types of annual crops is regulated by the cash available to pay for the input costs and the amount of family labour available. The decision to invest in perennial crops depends only on the capacity for investment, which is a function of the cash available and the family basic needs. After these steps, the model simulates for each farmer the harvesting

\footnotetext{
${ }^{4}$ But as the results of these decisions depend on the amount of cash available, farmers belonging to the same socioeconomic type usually have similar land-use strategies.
} 
period, the clearing of accounts (sale of cash crop products and deduction of the family consumption) and proceeds with the reimbursement of the loans to each lender (figure 4). When a farmer cannot reimburse a loan secured from the formal credit system, he will request credit from acquaintances and usurers. A farmer indebted with usurers assigns all his family labour to off-farm activities. If this is not enough to reimburse the loan for three successive years, this agent disappears, i.e. he/she is forced to sell his farm land and to leave the village.

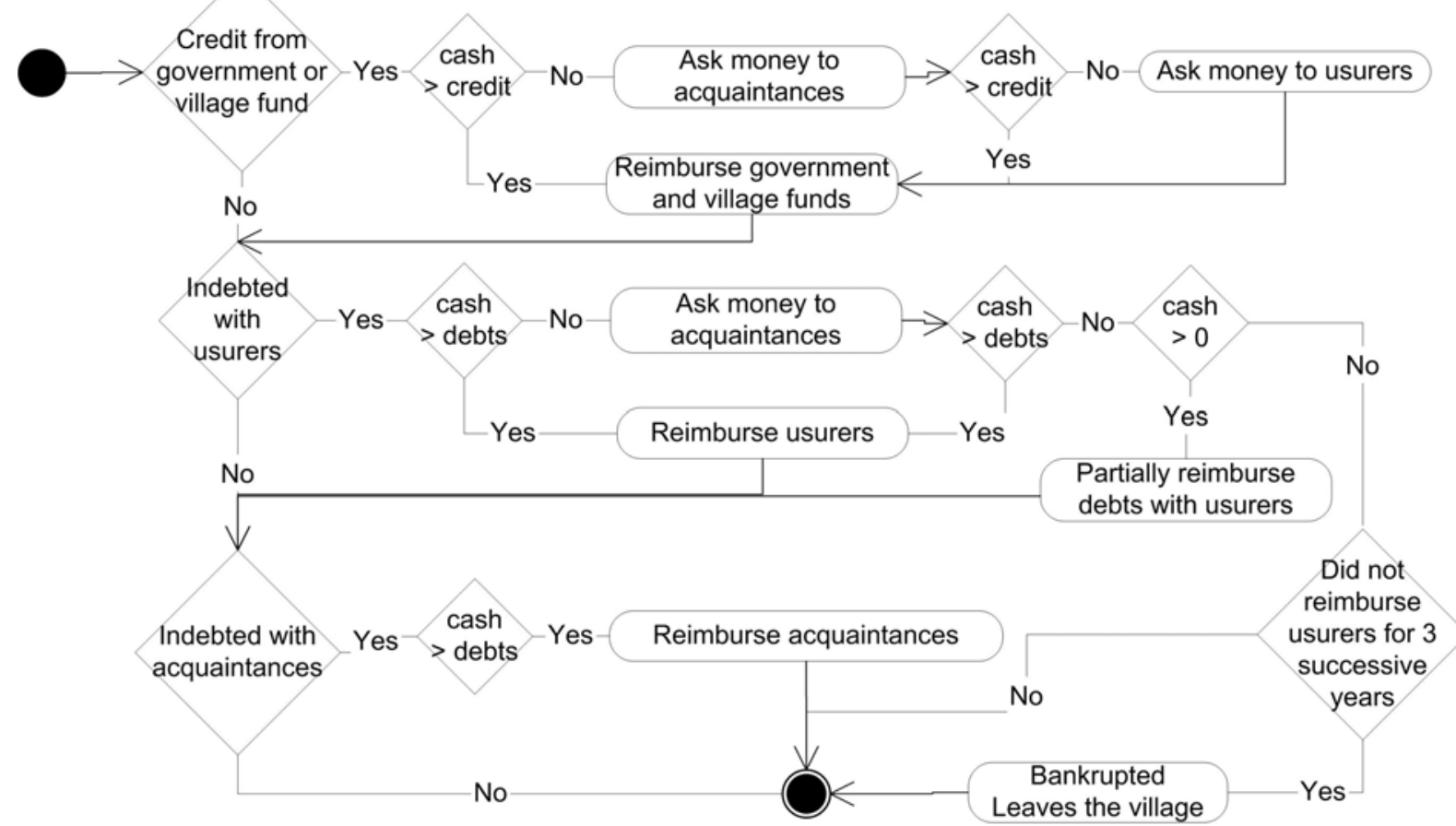

Figure 4. Dynamic diagram describing the process of reimbursement by the farmers

\section{Uncertainties}

This model is not a deterministic model. Each simulation will give different outputs. The main sources of uncertainties which are formalized with probability rules in the model are the following ones: (i) rainfall (which has an incidence on the risk of soil erosion), (ii) cash crop prices (random fluctuations within a range which is specific for each crop), (iii) off-farm opportunities (uncertainty of the labour market outside the village), and (iv) exceptional expenses which do not correspond to "rational" choices (such as the wedding of a child, as the social dimension of such an event is so important that even poor families will not hesitate to get indebted for it). However, when conducting the simulation experiments, to get more accurate results with a reasonable number of simulations, some of these stochastic elements such as the price fluctuations were neutralized and replaced by fixed series of numbers.

Outputs and indicators

Two major indicators were selected to assess the results of the simulations: (i) an agroecological indicator: the area under perennial crops for each of the three farm types (indicator for risk of soil erosion: the larger is the area under perennial crops, the lower is the risk of soil erosion), and (ii) a socioeconomic indicator: the percentage of type A farming households facing bankruptcy and having to leave the village against their will due to indebtedness (indicator for socio-economic differentiation through a process of impoverishment of the poorer villagers).

$\underline{\text { Verification and calibration }}$ 
The model verification and calibration were carried out by using a year-by-year monitoring of a set of indicators during simulations (crop combination per type of farm, on/off-farm labour employment, annual net incomes) and through their qualitative and quantitative comparison with the real circumstances recorded during the preliminary farm surveys.

Validation: respective roles of modellers and stakeholders

The process of validation differs for the entities' behaviour (local level) and the system's behaviour resulting from the interactions among these entities (global level). Within the framework of a project, Moss et al. (2000) defined validation as "the process by means of which model users develop confidence that the simulation models accurately capture their own assumptions" (p. 4). This is the way we validate the local level entities' behaviour in the model: we observe the farmers while they play to check our own assumptions about their behaviours, and we ask the farmers whether the model accurately capture their assumptions about their own behaviour and their environment. The game, very similar to its associated model, is a useful tool to "open the black box of the model" and to allow them to participate in its construction and validation. During the individual interviews following the gaming sessions, the players were asked whether some important dynamics related to the problem were missing or were not well represented compared to their assumptions about real circumstances. If a few suggestions for improvements were made and integrated in the model, in particular regarding the calibration of off-farm incomes, most of them found it realistic. Moreover, when asked weather they liked playing the game, and why, the most frequent answer given by the participants was "I liked playing the game because it is exactly like reality". We could also observe that players were very fast into the game, and this triggered lively and pertinent discussions among them about their real situation. According to Duke (1974), such observations are the best way to validate a game.

At the global level, the general properties of the system emerging from the interacting entities might capture some of our initial assumptions about the system, what is a form of validation. But the model might also reveal unexpected results. The researchers can consider these less intuitive emerging properties as new hypothesis on the system, and then look again at the real system, eventually discuss these hypotheses with the local stakeholders, and validate or reject them.

\section{Identification of scenarios according to stakeholders' suggestions}

The gaming session revealed the social inequity regarding investments in plantation crops because of unequal access to credit. The participants agreed that this situation reflected their real circumstances and constituted a problem. This collective agreement stimulated more exchanges and the following questions were raised: how to change the rules for formal and informal credit so that resource-poor (type A) farmers would have a better access to credit? Is it possible to change those rules? Would the smallholders benefit from such a change or would they face an even higher risk of bankruptcy? What would be the consequence of such changes for the medium-sized and larger landholders (type B and C farmers)? Following a lively discussion, they proposed to explore two possible solutions. An old player suggested solving the problem through informal credit, i.e. to set up broader and more socially heterogeneous networks of acquaintances to allow smallholders who are not yet acquainted with some wealthy farmers to get informal credit from them without interest (Figure 5). Younger players suggested changing the rules regulating the allocation of formal credit. In the current situation, type A farmers do not have access to the government fund, and the grace period is one year. These players suggested to introduce a 3 year long grace period (3 years is the duration from planting to first harvest of perennial crops in the model), and to allow type A farmers to borrow money from this source. 

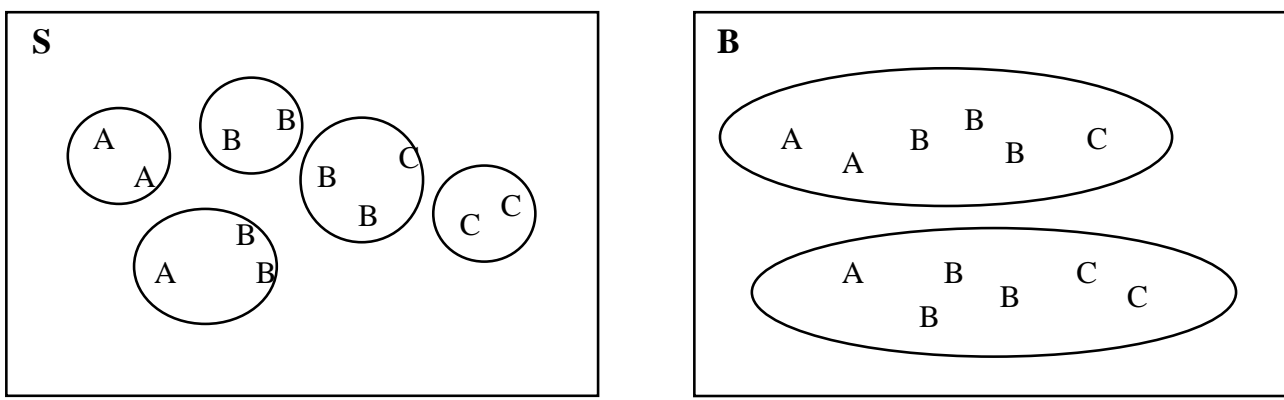

Figure 5. The two (S, B) types of social networks among three (A, B, C) main types of farms in the village used to regulate the distribution of informal credit. S: small and rather homogeneous networks (close to the real circumstances), $\mathrm{B}$ : broader and more heterogeneous networks. Type A, B and C farmers are respectively small, medium-sized and large landholders.

Six scenarios considered as pertinent to further explore the participants' suggestions were defined based on different combinations among the following three variables (Table 1):

(i) Duration for the reimbursement of loans secured from the government fund: one or three years $(1,3)$,

(ii) Mode of allocation of formal credit from the government fund among the three different types of farms : two main types of distribution are distinguished whether this source of credit is accessible to type A farmers or not (A for Access, NA for No Access),

(iii) Configuration of networks of acquaintances for access to informal credit: two situations displayed in Figure 5 (S for Small networks, B for Broad networks).

Table 1. Description of the six scenarios to be simulated

\begin{tabular}{|c|c|c|c|c|c|c|}
\hline Scenario & 1 & 2 & 3 & 4 & 5 & 6 \\
\hline $\begin{array}{l}\text { Duration of loans from government fund } \\
\text { (years) }\end{array}$ & 1 & 1 & 1 & 3 & 3 & 3 \\
\hline $\begin{array}{l}\text { Distribution of loans from government } \\
\text { fund (A or NA for Access or No Access } \\
\text { for type A farmers respectively) }\end{array}$ & NA & NA & A & NA & A & A \\
\hline $\begin{array}{l}\text { Amounts allocated to type } A, B \text { and } C \\
\text { farmers respectively (thousand } \\
\text { Bahts }{ }^{5} \text { /loan) }\end{array}$ & $0-10-20$ & $0-10-20$ & $5-8-19$ & $0-30-54$ & $12-18-54$ & $12-18-54$ \\
\hline $\begin{array}{l}\text { Configuration of networks of } \\
\text { acquaintances for informal credit (Small } \\
\text { or Broader, S or B respectively) }\end{array}$ & $S$ & B & S & S & S & B \\
\hline
\end{tabular}

Scenario 1 (1, NA, S) is the baseline scenario corresponding to the current situation: it is characterized by a 1 year grace period for the loans secured from the government fund, no access to this fund for smallholders - type A farmers-, and small and rather homogeneous networks of acquaintances (table 1). Scenario 2 (1, NA, B) explore new rules for informal credit, and more precisely broader networks of acquaintances. In scenarios 3, 4, and 5, networks of acquaintances remain small like in the baseline scenario, and new rules for the allocation of formal credit are tested.

\footnotetext{
${ }^{5}$ NB: in early 2006, 40 Thai baht $=1$ US\$.
} 
A preliminary exploration of the model allowed us to determine pertinent values for the amounts allocated to type A, B and C farmers respectively in the various scenarios (table 1). For 1 year long credit, NA distribution corresponds to the actual distribution of the government fund in the village, i.e. 0, 10 and 20 thousand Bahts for type A, B and C farmers respectively. Two constraints were taken into account to determine other distributions. First, we considered that the total budget allocated was fixed. For 3 year-long credit, to take into account general interest charges paid by the government, the total budget is slightly inferior to an amount equivalent to three times the total budget allocated for 1 year. Second, we considered that farmers would be allocated an amount which would not increase their risk of bankruptcy compare to current situation, i.e. which they would be able to reimburse in most cases.

\section{Results of simulation experiments}

Figure 6 displays the results of the simulations of the six selected scenarios. The graph displays the area under perennial crops in the 3 types of farm and the percentage of type A bankrupt farms at the end of the simulations, i.e. 15 years.

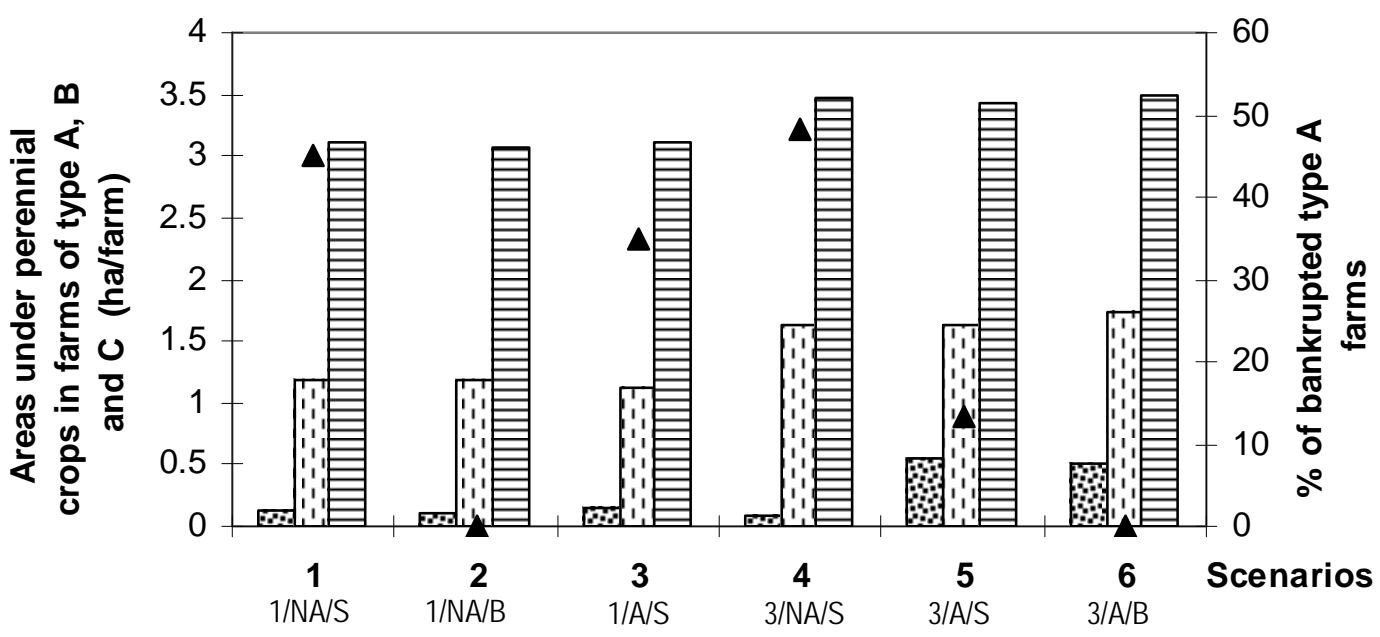

Perennial crops area in the 3 types of farms (left scale)

Type A: small and market integrated farms

$\square$ Type B: medium-sized and conservative farms $\boxminus$ Type C: large farms with diverse products

Note 1: scenarios are combinations of 3 variables : the duration of government credit (1 or 3 years), its distribution (A or NA for Accessible or Not Acessible to type A farmers), and the configuration of acquaintance networks (S or B for Small or Broad).

Note 2: average of the results of 20 repetitions of 15 step-long simulations for each scenario. We acknowledge that from a statistic point of view, it would have been preferable to run more than 20 repetitions. But given the numerous parameters of the model, it was not possible to conduct an exhaustive experiment plan. We decided therefore to neutralize some of the major stochastic elements of the model such as random price fluctuations by replacing them by fixed series of numbers, and run several simulations to check qualitatively that the intrinsic variability ${ }^{6}$ of a scenario was sufficiently low to allow comparisons between scenarios.

Figure 6. Effects of various rules for the allocation of formal and informal credit on the adoption of perennial crops and the risk of bankruptcy among different types of farmers

\footnotetext{
${ }^{6}$ For the scenario 1, the average areas for type A, B and C are respectively $0.12,1.18$ and 3.11 and the associated standard deviations are 0.06, 0.09 and 0.15 .
} 
The results of scenario 2 suggest that when social networks are broader, i.e. when smallholders have more the possibility to borrow money from acquaintances, the number of farms going bankrupt in the community is significantly reduced. But the results also suggest that this kind of informal credit does not allow these smallholders to increase their capacity to invest in plantation crops. This is because farmers borrow money from their acquaintances only for urgent needs and not for long-term investments like plantation crops. In scenario 3 (1, A, S), type A farmers have access to the government fund, but the duration of the loan remains 1 year. As seen in the previous section, the amount of this loan was chosen to be not too high to avoid an increase in the risk of bankruptcy because of farmers' inability to reimburse. The results of this scenario suggest that such a loan is not sufficient to allow type A farmers to increase significantly their area under plantations. This is because farmers have to wait three years before getting the first harvest of their perennial crops- and be able to reimburse a loan. In scenarios 4 and 5, the reimbursement period is 3 years. In scenario 4 (3, NA, S), type A farmers do not have access to this fund, and the total amount is shared among type $B$ and type $C$ farmers only. Results of simulation suggest that a 3 year long credit allows type B and C farmers to grow significantly more perennial crops. In scenario 5 (3, A, S), the total amount of credit is shared among the 3 types of farmers. This scenario suggests that if amounts allocated are not too high (compared to each type of farmer' reimbursement capacity), a credit with a 3 year long grace period allows all types of farmers (including smallholders) to grow more perennial crops. Thanks to the higher incomes generated by these plantations, the risk of bankruptcy for type A farmers is reduced to less than $15 \%$ (against almost $50 \%$ in the baseline scenario). However, only broader networks of acquaintances reduce completely their risk of bankruptcy, as illustrated by the results of scenario 6 (3, A, B). These 6 scenarios illustrate the specific and complementary roles played by formal and informal credit. With long duration loans, formal credit is potentially more efficient than informal credit to stimulate investment in perennial crops, whereas informal credit is potentially more efficient than formal credit to reduce the smallholders' risk of bankruptcy.

Table 2 provided details about the two types of informal exchanges among agents during the simulations, i.e. money borrowed from acquaintances and from usurers.

\section{Table 2. Farmer behaviour regarding informal credit during simulations.}

$\begin{array}{lcccc}\text { Scenarios } & \text { 1/NA/S } & \text { 1/NA/L } & \text { 3/A/S } & \text { 3/A/L } \\ \text { Money borrowed from acquaintances (Bahts) } & 5119 & 18526 & 2934 & 9657 \\ \text { (Remaining debts with acquaintances) (Bahts) } & (4144) & (13777) & (425) & \text { (651) } \\ \text { Money borrowed from money lenders (Bahts) } & 3454 & 0 & 2974 & 0\end{array}$

Note 1: as farmers who cannot reimburse their loans with usurers go to bankrupt, there are no remaining debts with usurers at the end of the simulations. Note 2: scenarios are combinations of 3 variables : the duration of government credit (1 or 3 years), its distribution (A or NA for Accessible or Not Accessible to type A farmers), and the configuration of acquaintance networks (S or B for Small or Broad).

Obviously, there are more exchanges among acquaintances in scenarios with broad networks of acquaintances than in scenarios with small networks of acquaintances. This result was quite intuitive. But less intuitive is that even when formal credit is accessible and adapted to all types of farmers, informal credit with acquaintances remains very important. This is because farmers easily borrow money from their acquaintances when they need to reimburse formal loans. But compare to a situation in which type A farmers do not have access to credit, there are much less remaining debts with acquaintances at the end of simulations when formal credit is more accessible. This is because under these scenarios, rules of formal credit allowed 
farmers to invest in perennial crops: they were able to reimburse their debts to their acquaintances thanks to the higher incomes from their plantations. However, it would be too simple to conclude that the suggested new rule of allocation of formal credit is the "best" solution. Indeed, indebtedness with usurers remains significant in scenario (3/A/S) and can only be reduced through broader networks of acquaintances. This confirms that formal and informal forms of credit play specific and complementary roles and should be jointly taken into account and analyzed when analyzing credit policies.

\section{Discussion}

Two questions are discussed in this section. First, what are the potential and limits of bottomup models such as MAS to explore the functioning of agricultural systems, in particular farm differentiation and rural credit dynamics? Second, what are the potential and limits of MAS models to support a bottom-up modelling approach, i.e. a participatory modelling process in which models are conceived and used with and for local stakeholders?

\section{A bottom-up model to analyze farm differentiation and rural credit MAS and farm differentiation}

Researchers in the field of agricultural economics have long been interested in heterogeneity among farms and have developed various methods to build farm typologies (Landais 1998). Such typologies provide a framework to analyse agricultural systems and to suggest solutions adapted to the different types of farmers who have different agro-ecological and socioeconomic means, constraints and strategies. Temporal dimensions are also taken into account to understand the processes of farm differentiation which are at the origin of the observed heterogeneity among farmers. Several simulation models were developed based on these frameworks. Most of them serve to assess the effects of various policies (price changes, subsidies, etc.) on the production system, often by maximising an economic function such as income through linear programming, as for example in (Dorward 1996). According to Landais (1998), these simulations have two major limitations. First they implicitly assume that the courses of evolution of the different farm types are independent of each other, and consequently overlook interactions such as commercial competition, competition for land, information circulation, etc. Second, the spatial dimension is not integrated despite its importance in the analysis of agricultural systems. With the recent wide spreading use of multi-agents systems, some researchers in agricultural economics start to use such models to address these pitfalls (Balmann 2000, Balmann et al. 2002, Berger 2001, Berger et al. 2006, le Canh et al. 2005). These researchers also chose MAS for their ability to integrate agroecological and socio-economic factors and developed MAS models representing comprehensively some regional agricultural systems. Agricultural economics is indeed an interdisciplinary research field by its nature. In these models, farmers are given various initial amounts of resources (land, animal, labour, capital) and can interact with each other, mainly on a land market in the case of Balmann (2000) and also for exchanges of water and diffusion of innovations in the case of Berger (2001). These authors observe structural changes, i.e. processes of socio-economic farm differentiation, under various policy scenarios. Based on a more or less similar framework of analysis of agricultural systems, the model presented in this paper share some similarities with their models. Farm differentiation is also at the core of our analysis, captured in the indicator of the percentage of poor farmers facing bankruptcy and having to leave the village against their will due to indebtedness. We show that informal loans among farmers within networks of acquaintance play a key role in this process of farm differentiation. Only "bottom-up" models such as MAS simulating interactions among heterogeneous entities could highlight such results. As Balmann et al. (2002) and Berger (2001), we emphasize the promising nature of MAS to bring new perspectives in the field of 
agricultural economics. But there are differences between the models developed by these authors and the one presented in this paper. First their models are deterministic while ours is stochastic to trigger the uncertain and unpredictable nature of complex systems. nature take into account uncertainties of complex systems. are stochastic As their models are based on linear programming, they are deterministic while The main one is that their models based on linear programming while ours areare deterministic and assume that farmers' decision making processes are driven by economic optimisation. Our model is stochastic and the model for farmers' decision making processes is based on real behaviours observed during the game, and validated through individual interviews with participants following the game. uncertainties of the differences is the level of complexity. Balmann (2000) concedes that the validation of such models is difficult and limited because of the too numerous factors interacting during a simulation. Researchers using the ComMod approach usually recommend keeping models as simple as possible to facilitate its validation (which remains a critical task anyway) and to make it more accessible to local stakeholders.

\section{MAS and analysis of rural credit}

Stating that in developing countries, informal credit sector did not disappear despite the development of formal credit sector, Bell (1990) first suggested a formal model analyzing the interactions between formal and informal credit sectors. Later on, several economists developed computable general equilibrium (CGE) models to analyze these interactions, all of them based on neoclassical economics assumptions (Bose 1998, Gupta and Chaudhuri 1997, Jain 1999). In these models, informal credit is restricted to exchange of money between usurers and farmers, usurers acting as intermediaries between banks and farmers who do not have access to formal credit resources. These authors demonstrate for example that the interest rates of formal and informal sectors are closely dependant and influence the coevolution of both sectors. Empirical observations from Coleman (2006) in north-east Thailand revealed that even pro-poor credit programs were often monopolized by rich usurers who then redistributed loans to poor farmers with higher interest rates. Our model also highlights some forms of interdependence and coexistence of formal and informal sectors. We show that if formal credit is more accessible but not adapted to smallholders (too high loans or too short reimbursement period), the number of usury contracts and the amounts of usurers loans sharply increase. But if formal credit is more accessible and adapted to smallholders, usury contracts decrease in number and amount. They do not disappear however because farmers still need to borrow money from usurers when they cannot reimburse formal loans on time. Having recourse to usurers is a way to compensate the rigidity of formal credit. But beside these results, our MAS model allows us to analyse another key aspect of informal credit which CGE models cannot grasp, that is informal exchanges of money among farmers within networks of acquaintances. And yet we show that such networks are major determinants of socio-economic differentiation among farmers: larger and more homogeneous networks of acquaintances significantly reduce the smallholders' risks of bankruptcy. This result is interesting because it is a key assumption which led to the development of micro-credit, an approach that has met with wide-spread acceptance. Micro-credit rests on the idea of loaning very small amounts of money to the poor and to organize borrowers into small groups of people who stand as guarantors for each other. Several MAS modellers come to the same type of conclusions regarding the positive role of social networks. Barreteau and Bousquet (2000) developed a multi-agent model representing irrigated systems in Senegal and emphasized the key role of exchanges of water and credit within social networks in the viability of this irrigated systems. Berger (2001) and Le Canh et al. (2005) who modelled exchanges of information about agricultural innovations among farmers suggested that wider social 
networks reduce socio-economic differentiation among farmers. All these examples illustrate the importance of social capital in the evolution of agricultural systems.

\section{A bottom-up modelling approach to accompany local stakeholders' learning process}

The RPG and MAS simulation tools stimulated a collective learning process among the villagers: they could better understand the complex situation at stake, what allowed them to suggest and explore scenarios for the management of rural credit that took into account both formal and informal sources, trade-offs between socio-economic \& ecological objectives, as well as equity issues among their heterogeneous farming community. After the workshop, villagers told us that requests for the establishment of a three year long grace period on loans from the government fund had actually already been sent to the government authorities by many rural communities across the country. "If tomorrow the government agrees to lend us money for three years, we would have to adapt rapidly to the new situation and these tools could be helpful" said a villager. During the interviews following the workshop, the participants mentioned two main benefits of the ComMod approach: they said it "helped to think ahead" and "to think together". "In our every daily life we do not have such opportunities", said a participant. Further analysis of the effects of the collective learning process stimulated by ComMod in terms of modified perceptions and interactions is available in (Barnaud et al 2006b). In the present article, we would like to emphasize that such a use of social simulations with and for local stakeholders has two major implications: first, the model should be well understood by them; second it should be constantly adapted to their preoccupations.

Genuine understanding of the model by the local stakeholders

This is necessary to ensure that local stakeholders are able to participate to the construction of the model through their critics and suggestions. Local stakeholders should also be aware of the limits of the models. They should not view the results of MAS simulations as quantitative predictions of the future. Instead, the model should be seen as a support to collectively discuss possible options before any technical decision is considered. Several factors favour such an understanding. The first one is the very nature of multi-agent systems which provide a natural and intuitive description of a system in terms of agents, objects and environment instead of mathematical equations. Moreover, in the ComMod approach, the associated RPG is a key tool to ensure that the model and, more importantly, its limits, are well-understood by the local stakeholders. Finally, the most useful models are not necessary the most comprehensive and sophisticated ones. Keeping models as simple as possible seems to favour their appropriation by their potential users.

Adaptation of the model to local stakeholders' needs and perceptions

Second, to increase the usefulness of these social simulations to local stakeholders, the models (the RPG as well as the computerized ones) need to be constantly updated and adapted to their representations and evolving preoccupations during the companion modelling process. Two time scales are distinguished in this process of adaptation of the model to the requirements of the users. Within a ComMod cycle, participants are asked whether the model fits to their representation of the problem at stake and the model is modified accordingly. From a Commod cycle to a following one, the use of a model by users stimulates discussions and might raise new questions. A new model is then built to fit to these emerging preoccupations. Each model is seen as a subjective extraction of the key relevant dynamics of the system at a particular moment of a collective learning process among a particular set of stakeholders with specific needs and expectations. Such an adaptive co-construction of the models with stakeholders implies modellers' willingness to adjust them to stakeholders' changing 
preoccupations, and the choice of very open and flexible modelling processes and tools. Multi-agent systems are particularly appropriate to respond to these needs as they offer the possibility to add or delete agents or to modify the model features and object behaviour without having to rebuild the whole model.

\section{Questions raised by such a bottom-up modelling approach}

This way to approach the notion of "model" raises questions such as: what would be the scientific status of a false model approved by the stakeholders? A first empirical way to answer to this question is to observe that among the numerous ComMod experiments conducted during the past 6-7 years in different regions of the world, such a situation never occurred. From a theoretical point of view, this empirical observation is not really surprising because one of the hypotheses of participatory approaches is precisely that all stakeholders have their reasons to act the way they act, and that the role of the scientist is to understand these reasons. However, the researchers should have a critical analysis of these reasons. If the risk to build a "false" model exists, it probably comes from the risk of manipulation of the modelling process by some powerful local stakeholders, or the risk to build a model that doesn't include the perceptions of the voiceless people. Further elaboration on the differentiated ability, and will, of the various local stakeholders to genuinely participate in the modelling process can be found in (Barnaud et al. 2006b).

\section{Conclusion}

Multi-agent systems open new modelling and analysis perspectives in several fields, such as social sciences, economics, environmental sciences and, more importantly, at their interactions. In the modelling approach adopted in this case study, the MAS model is coconstructed and used with and for local stakeholders facing a common renewable resource management problem. The objective of this approach named Companion Modelling (ComMod) is to facilitate collective learning between researchers and local stakeholders, and among local stakeholders themselves. Combining the use of MAS models with Role-Playing Games (RPG), this experiment aimed to facilitate collective decision-making about the local rules for the allocation of rural credit in a socially heterogeneous community of small farmers in mountainous northern Thailand. This paper presents the results of a series of simulations exploring the ecological, social and economic effects of various rules for formal and informal credit suggested by the villagers-participants.

Drawing on this case study, this paper first elaborates on the potential of bottom-up models such as MAS to analyze the functioning of agricultural systems, in particular farm differentiation and rural credit dynamics. First, because of the emphasis on interactions between social agents and their environment, MAS offer a framework to explore interactions between economic and ecological dynamics and to assess the trade-offs between both for various scenarios. This is a key dimension for sustainable development. The MAS model presented in this paper explored the effects of rural credit on soil erosion and farm differentiation. Second, MAS allow us to take into account interactions among individuals in the analysis of the functioning of the systems under study. This characteristic is even more MAS-specific than the previous one. We demonstrated in this paper that informal exchanges of money among farmers in the community significantly reduced the risks of bankruptcy for smallholders. MAS open new perspectives in the analysis of agricultural systems as they permit to introduce an overlooked but nevertheless fundamental aspect of these systems, i.e. social capital. Social capital refers to social relationships, norms and institutions. This notion allows to understand some behaviours considered as non-rational in conventional theory: for example an actor might take a decision which is not optimizing his income (like lending money to an acquaintance with no interest), but which fosters stable relationships or improve 
his reputation. At the macro-level, social capital is more and more considered as a key favouring factor for social equity and ecological sustainability (Rudd 2000). From a theoretical point of view, these findings confirm that conventional economic theories are not adapted to capture such nuances of complex ecological and economics systems (Arthur 1991, Arthur et al. 1997, Tesfatsion and Judd, 2006). To analyse the role of fundamental dynamics such as social capital, individuals should not be considered self-regarding and isolated and the behaviour of a group of individuals should not be represented by a single average meta-actor like in classical economic thinking. Instead, theories and methodologies should be developed to go beyond the traditional Homo Economicus (Jager et al 2000, Gintis 2000) and to analyse the effects at the macro-level of the interactions among heterogeneous actors at the microlevel (Kirman 1999).

In this experiment, MAS are used not only to analyse interactions among social actors, but also to stimulate such interactions to facilitate collective learning. This is the second question addressed in this paper: what are the potential and limits of MAS models to support a bottom-up modelling approach, i.e. a participatory modelling process in which models are conceived and used with and for local stakeholders? This experiment suggests that the usefulness of models relies much more on the modelling process than on the model itself, because a model is usually useless if it is misunderstood by its potential users, or if it does not respond to their current preoccupations. Two characteristics of MAS models favour such an appropriation by local stakeholders. First, they provide a natural and intuitive description of a system, representing the different stakeholders, their behaviour and their environment instead of mathematical equations. In the ComMod approach, this is reinforced by the association of the MAS with the RPG which is a way to open the black box of the model. Second, MAS offer a very flexible modelling framework which enables researchers to adapt rapidly the model to local stakeholders' representations and preoccupations. But the "one size fits all model” doesn't exist. And the use of MAS models described in this article has its own limits. The model is here seen as a support for collective discussions about possible options before any technical decision is considered. After such a brainstorming stage, if stakeholders need tools to quantitatively assess some specific infrastructures for example, other complementary kinds of models (MAS or other) might be necessary.

\section{Acknowledgements}

The authors would like to thank the villagers from Mae Salaep who participated to the workshops, Thanya and Panomsak Promburom from Chiang Mai University for their significant contribution in the implementation of the participatory modelling workshops, and two anonymous reviewers for their very useful suggestions.

\section{References}

Arthur, W.B., 1991. Designing Economic Agents that Act Like Human Agents: A Behavioral Approach to Bounded Rationality. American Economic Review Papers and Proceedings, 81 (2): 353-359.

Arthur, W.B., Durlauf, S.N. and Lane, D.A., 1997. The economy as an evolving complex system II. Addison-Wesley, Reading, MA.

Axelrod, R., 1997. Advancing the Art of Simulation in the Social Sciences. Lecture notes in Economics and Mathematical systems, 456: 21-40. 
Balmann, A., 2000. Modeling Land Use with Multi-Agent Systems. Perspectives for the Analysis of Agricultural Policies. In: R. S. Johnston (Editor), Microbehavior and

Macroresults: Proceedings of the Tenth Biennial Conference of the International Institute of Fisheries Economics and Trade, July 10-14, 2000, Corvallis, Oregon, USA.

Balmann, A., Happe, K., Kellermann, K. and Kleingarn, A., 2002. Adjustment costs of agrienvironmental policy switchings: an agent-based analysis of the German region Hohenlohe. In: M. A. Janssen (Eds), Complexity and ecosystem management: The theory and practice of multi-agent systems. Edward Elgar Publishers, 127-157.

Barnaud, C., Promburom, P., Bousquet, F. and Trébuil, G., 2006a. Companion Modelling to Facilitate Collective Land Management by Akha Villagers in Upper Northern Thailand. Journal of World Association of Soil and Water Conservation, J1 38-54.

Barnaud, C., Van Paassen, A. and Trébuil, G., 2006b. Power relations and participatory water management: lessons from a Companion Modeling experiment in a highland community of Northern Thailand. Paper presented at International Forum on Water and Food CPWF challenge programme Vientiane, Laos, 12-17 November 2006.

Barnaud C., Promburom T., Trébuil G and F. Bousquet, 2007a. Evolving simulation and gaming to support collective watershed management in mountainous northern Thailand. Simulation Gaming, 38: 398-420.

Barnaud, C., Promburom, T., Trébuil, G. and Bousquet, F., 2007b. Using simple models to accommodate multiple interests in water management : a companion modelling approach. In: B. Ekasingh, A. Jintrawet and S. Pratummintra (Eds), 2nd international conference on Asian Simulation and Modelling (ASIMMOD 2007). Chiang Mai University, Chiang Mai, Thailand, 248-255.

Barreteau, O. and Bousquet, F., 2000. SHADOC: a multi-agent model to tackle viability of irrigated systems. Annals of Operation Research, 14 139-162.

Barreteau, O., Bousquet, F. and Attonaty, J., 2001. Role-playing games for opening the black box of multi-agent systems: method and lessons of its application to Senegal River valley irrigated systems. Journal of Artificial Societies and Social Simulation, 4 (2): 5. $<$ http://www.soc.surrey.ac.uk/JASSS/4/2/5.html>

Barreteau, O., Antona, M., d’Aquino, P., Aubert, S., Boissau, S., Bousquet, F., Dare, W., Etienne, M., Le Page, C., Mathevet, R., Trébuil, G. and Weber, J., 2003. Our companion modelling approach. Journal of Artificial Societies and Social Simulation, 6 (2):1. $<$ http://www.soc.surrey.ac.uk/JASSS/6/2/1.html>

Bell, C., 1990. Interactions between Institutional and Informal Credit Agencies in Rural India. World bank economic review, 4 (3): 297-327.

Berger, T., 2001. Agent-based Spatial Models Applied to Agriculture: A Simulation Tool for Technology Diffusion, Resource Use Changes and Policy Analysis. Agricultural economics, 25 (2-3): 245-260. 
Berger, T., Schreinemachers, P. and Woelcke, J., 2006. Multi-agent simulation for the targeting of development policies in less-favored areas. Agricultural Systems, 88 28-43.

Bose, P., 1998. Formal-informal sector interaction in rural credit markets. Journal of Development Economics, 56 (2): 265-280.

Boulanger, P.-M. and Bréchet, T., 2005. Models for policy-making in sustainable development:The state of the art and perspectives for research. Ecological economics, 55: 337-350.

Bousquet, F., Bakam, I., Proton, H. and Le Page, C., 1998. CORMAS: Common-pool Resources and Multi-Agent Systems. Lecture Notes in Artificial Intelligence, 1416 : 826-838.

Bousquet, F., Barreteau, O., Le Page, C., Mullon, C. and Weber, J., 1999. An environmental modelling approach. The use of multi-agents simulations. . In: F. Blasco and A. Weill (Eds), Advances in Environmental and Ecological Modelling. Elsevier, Paris, 113-122.

Bousquet, F. and Le Page, C., 2004. Multi-agent simulations and ecosystem management: a review. Ecological Modelling, 176: 313-332.

Bousquet, F., Trébuil, G. and Hardy, B.E. (Editors), 2005. Companion Modeling and MultiAgent Systems for Integrated Natural Resource Management in Asia. International Rice Research Institute, Los Baños, Laguna, Philippines.

Coleman, B.E., 2006. Microfinance in Northeast Thailand: Who benefits and how much? World development, 34 (9): 1612-1638.

D'Aquino, P., Le Page, C., Bousquet, F. and Bah, A., 2003. Using Self-Designed RolePlaying Games and a Multi-Agent System to Empower a Local Decision-Making Process for Land Use Management: The SelfCormas Experiment in Senegal. Journal of Artificial Societies and Social Simulation 6(3): 5. http://www.soc.surrey.ac.uk/JASSS/6/3/5.html

Dorward, A.R., 1996. Modelling Diversity, Change and Uncertainty in Peasant Agriculture in Northern Malawi. Agricultural Systems, 51 (4): 469-486.

Duke, R. D., 1974. Gaming: the future's language. New York, SAGE Publications, Halsted Press.

Etienne, M., 2003. Sylvopast : a multiple target role playing game to assess negociation processes in sylvopastoral management planning. Journal of Artificial Societies and Social Simulation, 6 (2): 5. <http://jasss.soc.surrey.ac.uk/6/2/5.html>

Ferber, J., 1999. Multi-Agent Systems: An Introduction to Distributed Artificial Intelligence. Addison-Wesley Longman, Boston.

Gilbert, N. and Troitzsch, K., 1999. Simulation for the social scientist. Open University Press, Buckingham.

Gintis, H., 2000. Beyond Homo economicus: evidence from experimental economics. Ecological economics 35: 311-322. 
Gupta, M.R. and Chaudhuri, S., 1997. Formal Credit, Corruption and the Informal Credit Market in Agriculture: A Theoretical Analysis. Economica, 64 (254): 331-343.

Jager, W., Janssen, M., De Vries, H.J.M., De Greef, J. and Vlek, C.A.J., 2000. Behaviour in commons dilemmas: Homo economicus and Homo psychologicus in an ecological-economic model. Ecological economics, 35 (2000): 357-379.

Jain, S., 1999. Symbiosis vs. crowding-out: the interaction of formal and informal credit markets in developing countries. Journal of Development Economics, 59 (2): 419-444.

Janssen, M.A. and De Vries, H.J.M., 1998. The Battle of Perspectives: a multi-agent model with adaptive responses to climate change. Ecological Economics, 26 (1): 43-65.

Kirman, A., 1999. Aggregate activity and economic organisation. Revue européenne des sciences sociales, 37 (113) : 189-230.

Landais, E., 1998. Modelling Farm Diversity: New approaches to Typology Building in France. Agricultural Systems, 58 (4): 505-527.

Lansing, J.S. and Kremer, J.N., 1993. Emergent Properties of Balinese Water Temple Networks: Coadaptation on a Rugged Fitness Landscape. American Anthropologist, 95 (1): 97-114.

Le Canh, D., Ngien Nhi Gia, V., Le Anh, T. and Bousquet, F., 2005. Economic differentiation of rice and shrimp farming systems and riskiness case of Bac Lieu, Mekong Delta, Vietnam. In: F. Bousquet, G. Trébuil and B. Hardy (Eds), Companion Modeling and Multi-Agent Systems for Integrated Natrural Resource Management in Asia. International Rice Research Institute, Los Banos, 211-235.

Minar, N., R. Burkhart, C. Langton, and M. Askenazi. 1996. The Swarm simulation system: a toolkit for building multi-agent simulations. Working Paper 96-06-042, Santa Fe Institute, Santa Fe.

Moss, S., Downing, T. and Rouchier, J., 2000. Demonstrating the Role of Stakeholder Participation: An Agent Based Social Simulation Model of Water Demand Policy and Response. Report 00-76. Centre for Policy Modelling, Manchester Metropolitan University.

Moss, S. and Edmonds, B., 2005. Towards Good Social Science. Journal of Artificial Societies and Social Simulation, 8(4): 13 http://jasss.soc.surrey.ac.uk/8/4/13.html

North, M. J., N. T. Collier and J. R. Vos, 2006. Experiences Creating Three Implementations of the Repast Agent Modeling Toolkit, ACM Transactions on Modeling and Computer Simulation 16(1): 1-25.

Rouchier, J. and Bousquet, F., 1998. Non merchant economy and multi-agent systems : an analysis of structuring exchanges. Lecture Notes in Articicial Intelligence, 1534: 111-124.

Rudd, M.A., 2000. Live long and prosper : collective action, social capital and social vision. Ecological economics, 34 (234): 131-144. 
Tesfatsion, L. and K. Judd (Eds.), 2006. Handbook of Computational Economics, Volume 2: Agent-Based Computational Economics. Amsterdam, North-Holland.

Trébuil, G., Kam, S.P., Turkelboom, F. and Shinawatra, B., 1997. Diagnoses at Field, Farm and Watershed Levels in Diversifying Upland Agroecosystems: Towards Comprehensive Solutions to Farmers' Problems. In: M. J. Kropff, P. S. Teng, P. K. Aggarwal, J. Bouma, B. A. M. Bouman, J. W. Jones and H. H. v. Laar (Eds), Systems Approaches for Sustainable Agricultural Development: Applications of Systems Approaches at the Farm and Regional Levels. Proceedings from IRRI International Symposium. Kluwer Academic Publishers, International Rice Research Institute, 99-114.

Trébuil, G., Shinawatra-Ekasingh, B., Bousquet, F. and Thong-Ngam, C., 2002. Multi-agent systems companion modelling for integrated watershed management: a northern Thailand experience. In: X. Jianchu and S. Mikesell (Eds), Landcapes of diversity. Proceedings of 3rd International Conference on Montane Mainland Southeast Asia (MMSEA 3) Yunnan Science and Technology Press, China, Lijiang, Yunnan, China, 349-358.

Wilensky, U. (1999). NetLogo. http://ccl.northwestern.edu/netlogo/. Center for Connected Learning and Computer-Based Modeling, Northwestern University, Evanston, IL. 